\title{
Pudrición de raíces y tallo de la soya por Phytophthora sojae Kaufm. \& Gerd. en la altillanura plana del departamento del Meta
}

\author{
Marcela López-Casallas ${ }^{1} \oplus$, Yudy Alejandra Guevara-Castro ${ }^{1} \odot$, Yeinny Carolina Pisco-Ortíz ${ }^{1} \mathbb{0}$, \\ Isabel Moreno Cabrera ${ }^{2}$, Nathali López-Cardona ${ }^{1}$ (1)
}

${ }^{1}$ Centro de Investigación La Libertad, Km 17, Vía Puerto López, Meta, Colombia; ${ }^{2}$ Centro de Investigación Palmira, Diagonal a la intersección de la Carrera, 36A con Calle 23, Palmira, Valle del Cauca, Colombia.

Correspondencia: Nathali López Cardona(nlopezc@agrosavia.co)

Data de chegada: 24/10/2019. Aceito para publicação em: 15/03/2020.

$10.1590 / 0100-5405 / 230356$

\section{RESUMEN}

López-Casallas, M.; Guevara-Castro, Y.A.; Pisco-Ortíz, Y.C.; Cabrera, I.M.; López-Cardona, N. Pudrición de raíces y tallo de la soya por Phytophthora sojae Kaufm. \& Gerd. en la altillanura plana del departamento del Meta. Summa Phytopathologica, v.46, n.2, p.113-120, 2020.

El oomycete Phytophthora sojae ha sido reportado como causante de "Damping off" en pre y post emergencia, y pudrición en tallos y raíces en cultivos de soya a nivel mundial. Con el incremento del área sembrada de soya en Colombia en la altillanura plana del departamento del Meta y a la presencia de condiciones ambientales altamente favorables se han observado síntomas de daños en plántulas que pueden ser causados por un complejo de patógenos dónde se incluye a $P$. sojae. Este trabajo tuvo como objetivo identificar el agente causal de la pudrición de raíces y tallo en cultivos de soya en la altillanura plana del Meta, a partir del diagnóstico microbiológico y molecular de 84 muestras de tejido afectado. La caracterización morfológica del agente causal y macroscópica de las colonias se realizó en el medio V8 modificado. La identificación molecular fue realizada mediante la amplificación de la región ITS ("The internal transcribed spacer region") presente en el genoma de hongos y omycetes. Se realizó análisis filogenético comparando las secuencias ITS de diferentes especies del género Phytophthora reportadas en estudios anteriores y depositadas en el GenBank, de aislamientos de P. sojae de diferentes regiones geográficas y las secuencias de $P$. sojae obtenidas en este estudio. De las 84 muestras analizadas en el período 2015-2017, siete (7) muestras correspondientes al $8 \%$ presentaron síntomas típicos de pudrición de raíz y tallo y fueron atribuidos a $P$. sojae confirmando los postulados de Köch. Las 77 muestras restantes, correspondientes al $92 \%$ presentaron síntomas del complejo "Damping off" y fueron asociados a Pythium spp. y Fusarium spp. Este es el primer registro de la presencia de $P$. sojae y su participación como agente causal de las pudriciones de raíces y tallo en lotes comerciales de soya en la altillanura del departamento del Meta.

Palabras clave: Glycine max L.; ITS; Oomycetes; Fusarium sp.; Damping off.

\section{RESUMO}

López-Casallas, M.; Guevara-Castro, Y.A.; Pisco-Ortíz, Y.C.; Cabrera, I.M.; López-Cardona, N. Podridão da raiz e da haste por Phytophthora sojae Kaufm. \& Gerd. no Altillanura plana do departamento de Meta. Summa Phytopathologica, v.46, n.2, p.113-120, 2020.

A oomiceto Phytophthora sojae tem sido relatada como causadora de "amortecimento" em pré e pós-emergência, e apodrece em caules e raízes em lavouras de soja em todo o mundo. Com o aumento da área plantada com soja na Colômbia na região plano do departamento de Meta e à presença de condições ambientais altamente favoráveis, foram observados sintomas de danos às mudas que podem ser causados por um complexo de patógenos onde P. sojae está incluída. Este trabalho teve como objetivo identificar o agente causador da podridão radicular e do caule em lavouras de soja na região do departamento Meta, a través do diagnóstico microbiológico e molecular de 84 amostras de tecido afetado. A caracterização morfológica do agente causador e macroscópico das colônias foi realizada no meio V8 modificado. A identificação molecular foi realizada por amplificação da região ITS. Para a comparação filogenética, foram utilizadas sequências ITS relatadas em estudos anteriores e depositadas no GenBank para diferentes espécies do género Phytophthora, de isolados da espécie P. sojae de diferentes regiões geográficas e das sequências de P. sojae obtidas neste estudo. Das 84 amostras analisadas no período 2015-2017, sete (7) amostras correspondentes a $8 \%$ apresentaram sintomas típicos de podridão radicular e caule e foram atribuídas a $P$. sojae, confirmando os postulados de Köch. As 77 amostras restantes correspondentes a $92 \%$ apresentaram sintomas do complexo "Damping off" e foram associadas ao Pythium spp., e Fusarium spp. Este é o primeiro registro da presença de $P$. sojae e a sua participação como agente causal da podridão radicular e do caule em lotes comerciais de soja no Altillanura plana do departamento de Meta.

Palavras-chave: Glycine max L.; ITS; Oomycetes; Fusarium sp.; Damping off.

\section{ABSTRACT}

López-Casallas, M.; Guevara-Castro, Y.A.; Pisco-Ortíz, Y.C.; Cabrera, I.M.; López-Cardona, N. Root and Stem Rot by Phytophthora sojae Kaufm. \& Gerd. in the eastern high plains of Meta Department. Summa Phytopathologica, v.46, n.2, p.113-120, 2020.

The oomycete Phytophthora sojae has been reported to cause "Damping off" during pre and post-emergence, as well as root and stem rot in soybean crops worldwide. The increase in the soybean planted area in Colombia, in the region of eastern high plains of Meta Department, and the presence of highly favorable environmental conditions led to the appearance of seedling damage symptoms, which could be caused by a pathogen complex that includes $P$. sojae. This study aimed to identify the causal agent of root and stem rot in soybean crops in the region of Meta Department through microbiological and molecular diagnosis of 84 affected tissue samples. Morphological characterization of the causal agent and macroscopic characterization of colonies were performed in modified V8 medium. Molecular identification was done by amplification of the ITS region. Phylogenetic comparison employed ITS sequences reported in previous studies and deposited in the GenBank for different species of the genus Phytophthora, isolates of the species $P$. sojae from different geographical regions and the sequences of $P$. sojae obtained in this study. Of the 84 samples analyzed during 2015-2017, seven (7) samples corresponding to $8 \%$ showed typical symptoms of root and stem rot, which were attributed to $P$. sojae, confirming Koch's postulates. The remaining 77 samples corresponding to $92 \%$ presented symptoms of the "Damping off" complex and were associated with Pythium spp. and Fusarium spp. This is the first report of the presence of $P$. sojae and its participation as a causal agent of root and stem rot in commercial areas of soybeans in the eastern high plains of Meta Department.

Keywords: Glycine max L.; ITS; Oomycetes; Fusarium sp.; Damping off. 
La pudrición de raíces de soya causada por el oomycete Phytophthora sojae, se considera una de las enfermedades más limitantes del cultivo en las regiones tropicales. De acuerdo con Dorrance (2018) y Dorrance et al. (2008) este patógeno se caracteriza por su alta especificidad de hospedero que incluye la soya y algunas flores silvestres del género Lupinus causando daños en pre y post emergencia que afectan semillas, raíces y tallos de plántulas, e infecciones en plantas adultas. Las pérdidas en rendimiento pueden alcanzar el $100 \%$ si los cultivares susceptibles se siembran en lotes con presencia de inóculo y deficiente de drenaje. La incidencia de la enfermedad puede variar de acuerdo con la época de siembra, variedad de soya cultivada, frecuencia e intensidad de las lluvias, retención de humedad en el suelo, contenido de arcillas, tipo de labranza y sistemas de siembra. En países como Argentina y Brasil la incidencia en cultivares susceptibles ha alcanzado entre el 50\% y 70\% de afectación (Vallone, et al. (1999); Wrather et al. (2001). Desde 1996 hasta 2014, aproximadamente 20,5 millones de toneladas métricas anuales se perdieron debido a la pudrición de la raíz y el tallo en soya, con una pérdida anual promedio de más de 1,1 millones de toneladas métricas (Wrather et al. 2001). En Colombia, P. sojae se reportó por primera vez en el Valle del Cauca en el año de 1985 (Granada y Varón de Agudelo, 1996) y seis años después en los llanos orientales específicamente en el piedemonte llanero (Montoya, 1991). En esta misma región, en el año 2000, la enfermedad presentó niveles de incidencia cercanos al $41 \%$, registrando pérdidas del $26 \%$ de la producción en la variedad CORPOICA Orinoquia 3 (Tapiero y Rey, 2006). En la actualidad, el cultivo de soya se ha expandido a la altillanura plana del departamento del Meta en negocios agroindustriales, lo que ha llevado al establecimiento de nuevas áreas sembradas y la introducción de cultivares con alto potencial productivo. En razón de lo anterior, se ha generado un incremento de síntomas asociados con "Damping off” y pudrición de raíces y tallo que pueden ser causados además de $P$. sojae, por otros microorganismos de suelo como Fusarium sp., Pythium sp., Rhizoctonia sp. y Sclerotium sp., lo que dificulta su diagnóstico en campo y genera confusión respecto al agente causal de la enfermedad. Lo anterior, sumado a la ausencia de registros sobre la presencia de $P$. sojae en la altillanura del Meta, soportan el desarrollo de este trabajo de investigación, el cual esclarece la etiología de la pudrición de raíces y tallos de soya en la ecorregión de la altillanura del departamento de Meta.

\section{MATERIALES Y MÉTODOS}

\section{Sitio de estudio y muestreo}

La toma de muestras se realizó en lotes experimentales del Centro de Investigación Carimagua y la sede Taluma de la Corporación Colombiana de Investigación Agropecuaria-AGROSAVIA y en 9 fincas productoras de soya en los municipios de Puerto Gaitán y Puerto López en el departamento del Meta. Entre el 2015 y 2017 se recolectaron un total de 84 muestras, de las cuales 16 correspondían a suelo y 68 correspondían a plántulas de soya con síntomas de "Damping off" y pudrición de raíces y tallo. La colecta de muestras se realizó en estado vegetativo (V1 a V3) y la fecha de muestreo se ajustó dependiendo del ciclo biológico de la variedad sembrada. El muestreo se realizó en el lote con mayor incidencia de la enfermedad de acuerdo con información suministrada por el productor.

\section{Aislamiento a partir de tejido vegetal}

El tejido vegetal afectado fue lavado con abundante agua de grifo, luego desinfectado con hipoclorito de sodio al $1 \%$ por 1 minuto, enjuagado 2 veces con agua destilada e inmerso en una solución de etanol al $70 \%$ por 1 minuto. Después fue lavado 2 veces con agua destilada y secado a temperatura ambiente hasta su siembra en medio de cultivo. En agar V8 (180 mL/L jugo V8, 2 g/L CaCO, $15 \mathrm{~g} / \mathrm{L}$ agar, Rifampicina 750 ppm; $\mathrm{pH}$ 6.5) se dispuso una porción de material vegetal correspondiente a $70 \%$ de tejido sano y $30 \%$ enfermo fue sembrada directamente sobre la superficie de placas de agar y las cajas se incubaron a temperatura ambiente $\left(28^{\circ} \mathrm{C}\right)$ por 10 días [AGROSAVIA, $(2017,2018)]$.

\section{Aislamiento a partir de suelo por el método de bioensayos}

Se colectaron muestras de suelo en lotes con historial de la enfermedad, que además presentaron compactación y problemas de drenaje. Cada muestra estuvo compuesta por 20 submuestras, las cuales fueron tomadas con barreno a $15 \mathrm{~cm}$ de profundidad. Cada muestra se secó a temperatura ambiente y tamizó a $2 \mathrm{~mm}$; con el tamizado se llenaron materas entre $1 \mathrm{a} 2 \mathrm{~kg}$. anegándolas con agua corriente. Posteriormente, las materas se depositaron en bolsas plásticas negras y se incubaron a temperatura ambiente por un período de dos semanas. Después del tiempo de incubación, en cada maceta, el suelo se labró a $1 \mathrm{~cm}$ de profundidad. Quince semillas de los cultivares susceptibles CORPOICA Orinoquia 3, Sloan y Williams, se sembraron a $1 \mathrm{~cm}$ de profundidad. La superficie del suelo se cubrió con vermiculita gruesa saturada con $250 \mathrm{~mL}$ de agua, y las macetas fueron puestas de nuevo en bolsas plásticas. Cuando las semillas germinaron, y las raíces alcanzaron aproximadamente $5 \mathrm{~cm}$ de longitud, el suelo se inundó con agua corriente por 24 horas, luego se drenó y se incubó a temperatura ambiente en condiciones de casa de malla. (Temperatura máxima promedio de $30,9{ }^{\circ} \mathrm{C}$, Temperatura mínima promedio de $22,01{ }^{\circ} \mathrm{C}$, y Humedad Relativa promedio de 81,45\%). Se realizaron observaciones diarias y se colectaron plántulas con síntomas de marchitamiento o pudrición de raíz y tallo para obtener aislamientos presuntivos de Phytophthora sp. (Dorrance, 2018).

\section{Aislamiento a partir de suelo con cebo}

Se pesaron $9 \mathrm{~g}$ de cada muestra de suelo. Se agregó $1 \mathrm{~mL}$ de agua destilada estéril y se introdujeron cotiledones de las variedades susceptibles CORPOICA Orinoquia 3 y Williams, provenientes de plantas en estado de desarrollo V3 cultivadas en invernadero. Se dejaron incubando a temperatura ambiente durante 48 horas a $\pm 28^{\circ} \mathrm{C}$. Se tomaron los cotiledones que evidenciaron algunos síntomas de necrosis o pudrición y se lavaron con abundante agua durante 20 minutos. Los trozos de tejido se sembraron en medio V8 $(200 \mathrm{~mL}$ de Jugo V8, $3 \mathrm{~g}$ de $\mathrm{CaCO}_{3}$, $15 \mathrm{~g}$ Agar Agar, $100 \mathrm{~mL}$ de Agua destilada) por debajo del agar con el fin de disminuir la contaminación por bacterias y se incubaron en oscuridad durante 1 semana. Cuando se evidenció la presencia de crecimiento micelial se realizó la purificación de colonias en medio V8 modificado (Jugo V8 $200 \mathrm{~mL}, \mathrm{CaCO}_{3} 3 \mathrm{~g}$, agar $15 \mathrm{~g}$, rifampicina $750 \mathrm{ppm}$, ampicilina $20000 \mathrm{ppm}$, penicilina 10000 ppm) y Agar PCBN (Jugo V8 $40 \mathrm{~mL}, \mathrm{CaCl}_{2} 0.6 \mathrm{~g}, \mathrm{C}_{12} \mathrm{H}_{22} \mathrm{O}_{11} 1 \mathrm{~g}$, extracto de levadura $0.2 \mathrm{~g}$, colesterol $0.01 \mathrm{~g}$, Agar $20 \mathrm{~g}$ y $1 \mathrm{~mL}$ de los siguientes antibióticos y fungicidas a partir de una solución stock de ampicilina, rifampicina, penicilina, benomyl, pentacloronitrobenzeno, fludioxonil y metalaxil-M). (Dorrance, 2018).

\section{Purificación}

Se efectuó mediante pases consecutivos a placas situando los aislamientos por debajo del medio V8 modificado y PCNB. 


\section{Identificación morfológica}

Mediante improntas de una porción de cada colonia y con azul de lactofenol se realizó observación microscópica de estructuras en microscopio óptico a 40X de aumento. La identificación de características microscópicas del patógeno y macroscópicas de las colonias se realizaron de acuerdo con Erwin \& Ribeiro, (1996).

\section{Caracterización molecular}

El micelio de los aislamientos presuntivos de $P$. sojae crecido en medio de cultivo solido V8 modificado y Agar Zanahoria (Drenth y Sendall, 2001) durante 8 días a $28^{\circ} \mathrm{C}$, fue empleado para la extracción de ADN. El tejido fue macerado con nitrógeno líquido y se siguió el protocolo de extracción de ADN del mini kit para plantas de Qiagen ${ }^{\circledR}$. La calidad y cantidad de ADN fue visualizada en gel de agarosa al 1,5\%, y la concentración en $\mathrm{ng} / \mathrm{uL}$ se determinó utilizando el NanoDrop One (Thermo Fisher Scientific) (Guevara, 2017). Se realizó la amplificación de la región conservada ITS siguiendo las condiciones reportadas por Ristaino et al. (1998). Se emplearon los pares de cebadores ITS5 (5'GGAAGTAAAAGTCGTAACAAGG3') e ITS4 (5' TCCTCCGCTTATTGATATGC 3'). Cada reacción de PCR se calculó para un volumen final de $25 \mathrm{uL}$, utilizando $1 \mathrm{X}$ del Go Taq Green Master Mix (Promega), 8uM de cada primer (F y R) y $3 \mathrm{uL}$ de $\mathrm{ADN}(20 \mathrm{ng} / \mathrm{uL})$. Cada amplificación se realizó en un termociclador PTC-100 (MJ Research, Inc., Watertown, MA) utilizando las siguientes condiciones: Un paso de desnaturalización a $95^{\circ} \mathrm{C}$ durante 3 minutos, seguido por 34 ciclos de desnaturalización $\left(95^{\circ} \mathrm{C}\right.$ por 1 minuto), hibridación $\left(52^{\circ} \mathrm{C}\right.$ por 30 segundos), elongación ( $72^{\circ} \mathrm{C}$ por 1 minuto), y un ciclo final de extensión $\left(72^{\circ} \mathrm{C}\right.$ por 10 minutos) (11). El producto de los amplificados se visualizó en gel de agarosa al 1,5\%. Las muestras presuntivas fueron preparadas para su envío a secuenciación, y una vez obtenidos los electroferogramas se realizó la identificación de aislamientos en la base de datos NCBI por homología utilizando la herramienta BLAST de acuerdo con Guevara, (2017).

\section{Comparación filogenética}

Para la comparación filogenética de las secuencias ITS de los aislamientos de P. sojae obtenidos en este estudio, se usaron secuencias de las regiones ITS que han sido depositados en el GenBank, y que corresponden a especies tipo del género Phytophthora y a aislamientos confirmados de $P$. sojae de diferentes regiones geográficas. Una vez obtenido el alineamiento consenso de secuencias en el programa Genious v 8.1.9, el mejor modelo de sustitución de nucleótidos fue seleccionado con base en los puntajes más bajos del criterio de información bayesiano (BIC) que describen el mejor patrón de sustitución de acuerdo con Guevara, (2017). Otros valores también considerados fueron el AICc (Criterio de información de Akaike, corregido), el valor de Máxima verosimilitud ( $\mathrm{lnL}$ ) y el número de parámetros (incluidas las longitudes de rama) (Erwin y Ribeiro, 1996). Los análisis fueron realizados utilizando el programa MEGA 6.0 (Tamura et al. 2013). La filogenia fue estimada mediante Inferencia Bayesiana en el programa Genious v 8.1.9 con la aplicación Mr. Bayes. Bajo esta metodología se eligió la filogenia con mayor probabilidad posterior como resultado del análisis de toda la distribución de probabilidades posteriores usando el parámetro Metropolis Markov Chain Monte Carlo (MCMC) (Guevara, 2017). El análisis se realizó por duplicado, cada uno empezando en un árbol diferente seleccionado al azar; se corrieron dos cadenas simultáneas por
10.000.000 generaciones, con muestreo de árboles cada 1000 generaciones (resultando en un total de 10.000 árboles). Finalmente, el árbol filogenético consenso resultante fue a-justado a un límite de probabilidad posterior de $\geq 0,5$, para determinar la divergencia de acuerdo con Guevara, (2017).

\section{Pruebas de patogenicidad}

Con el propósito de confirmar mediante los postulados de Köch la causalidad de la enfermedad, se inocularon plántulas de 10-15 días de edad del cultivar Williams como testigo susceptible universal y CORPOICA Orinoquia 3 como testigo susceptible local. Se emplearon dos técnicas: Inoculación directa al hipocótilo con discos de agar, desarrollada por Laviolette \& Athow (1981) con modificaciones para los aislados 5057301, 5057302, 5057303, e inoculación con palillos colonizados del microorganismo de acuerdo con Keeling (1982), Moreira \& Arrabal (2016) para los aislamientos 5057305, 5057306, 5057307 y 5057308. Para ambos métodos, se inocularon plantas entre 11 a 15 días después de la siembra. Después de la inoculación, las plantas se mantuvieron en cámara húmeda por 48 horas y se evaluaron diariamente hasta la aparición de síntomas. Finalmente, se procedió al re-aislamiento del patógeno a partir de plantas sintomáticas para la confirmación de características macroscópicas y microscópicas del patógeno.

\section{RESULTADOS Y DISCUSION}

De las 84 muestras analizadas provenientes de la altillanura plana del departamento del Meta, 7 muestras correspondientes al 8\%, presentaron síntomas típicos de pudrición de raíz y tallo de donde se obtuvieron aislamientos de $P$. sojae. Las plantas infectadas en estados avanzados de la enfermedad se marchitan y mueren (Figura 1).

Las restantes 77 muestras, correspondientes al 92\%, presentaron síntomas del complejo "Damping off" asociado a Pythium spp. y Fusarium spp. Las plántulas con "Damping off” presentaron pudrición de radícula y necrosis del hipocótilo que avanza hasta afectar los cotiledones (Figura 2). Phytophthora sojae no fue identificado en ninguna de las muestras que presentaron este síntoma.

Los aislamientos de $P$. sojae presentaron macroscópicamente micelio aéreo de textura algodonosa y color blanco (Figura 3A). Microscópicamente presentaron micelio hialino cenocítico y presencia de oosporas pleróticas ovoides, con diámetros promedio de 31,4 $\mu \mathrm{m}$ (Figura 3B), características que coinciden con la descripción de Erwin \& Ribero (1996) para la especie Phytophthora sojae. Los postulados de Köch fueron comprobados al re-aislar el patógeno de los tejidos enfermos de plantas inoculadas, tanto por el método de discos de agar como por el de palillos colonizados, los cuales fueron efectivos para reproducir síntomas en las variedades susceptibles de soya Williams y CORPOICA Orinoquia 3 (Figura 4).

Las secuencias de la región ITS de los aislamientos obtenidos en este estudio presentaron una homología superior al $98 \%$ con Phytophthora sojae al ser analizadas por la herramienta BLAST en la base de datos del GenBank. Una vez obtenido el alineamiento múltiple de secuencias de $P$. sojae y de referencia para la filogenia molecular, el mejor modelo de sustitución de nucleótidos para el análisis bayesiano fue el de Hasegawa-Kishino-Yano (HKY) (MEGA 6.0) con base a Tamura, (2013). En la Figura 5 se presenta el árbol consenso obtenido del análisis de inferencia bayesiana para la región ITS de 691 pb de los aislamientos identificados como $P$. sojae, conformado por siete (7) 

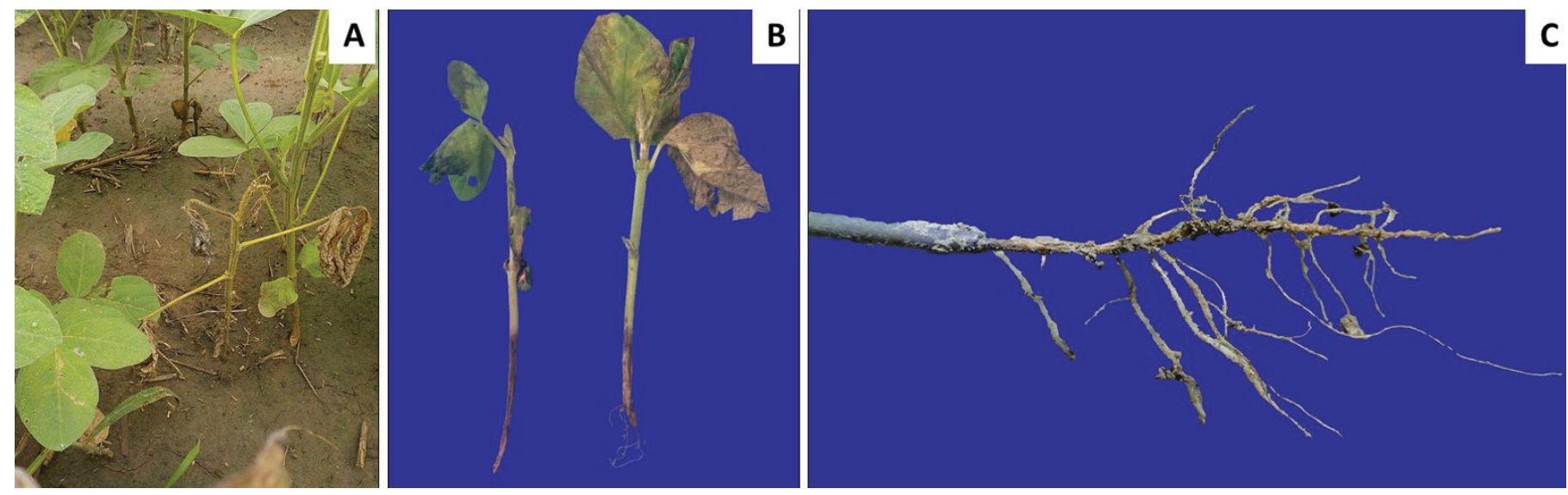

Figura 1. Síntomas típicos causados por Phytophthora sojae en la variedad de soya Panorama 29i. A. Marchitez de plántulas B. Pudrición de raíces y tallo en plántulas. C. Pudrición de raíz. Fuente: AGROSAVIA (2018).
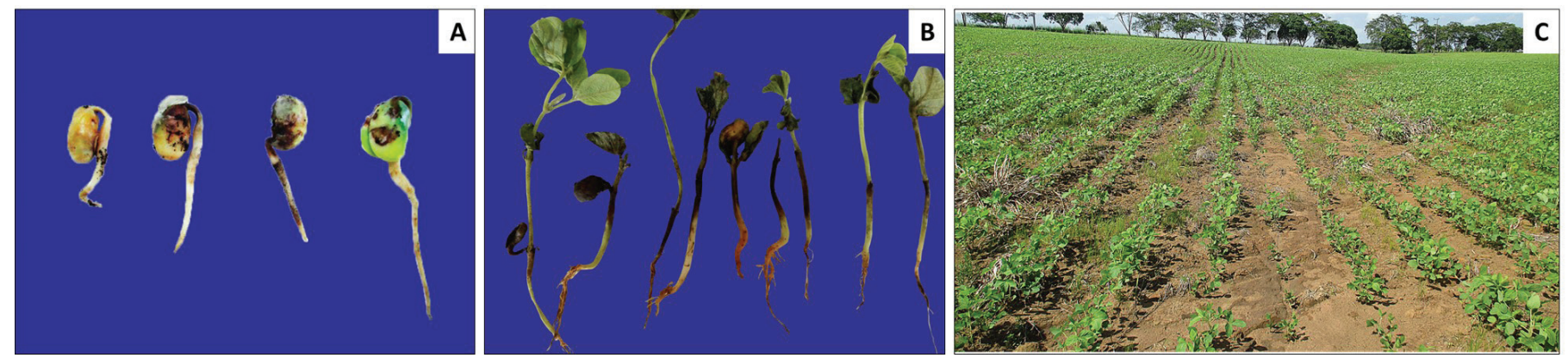

Figura 2 Síntomas típicos de Damping off en soya. A. Pudrición de radícula y necrosis del hipocótilo en la variedad CORPOICA Achagua 8. B. Necrosis del cuello y tallo de plántulas con escases de raíces. C. Foco de infección con pérdidas de plántulas en la variedad de soya Panorama 29i. Fuente: AGROSAVIA (2018).

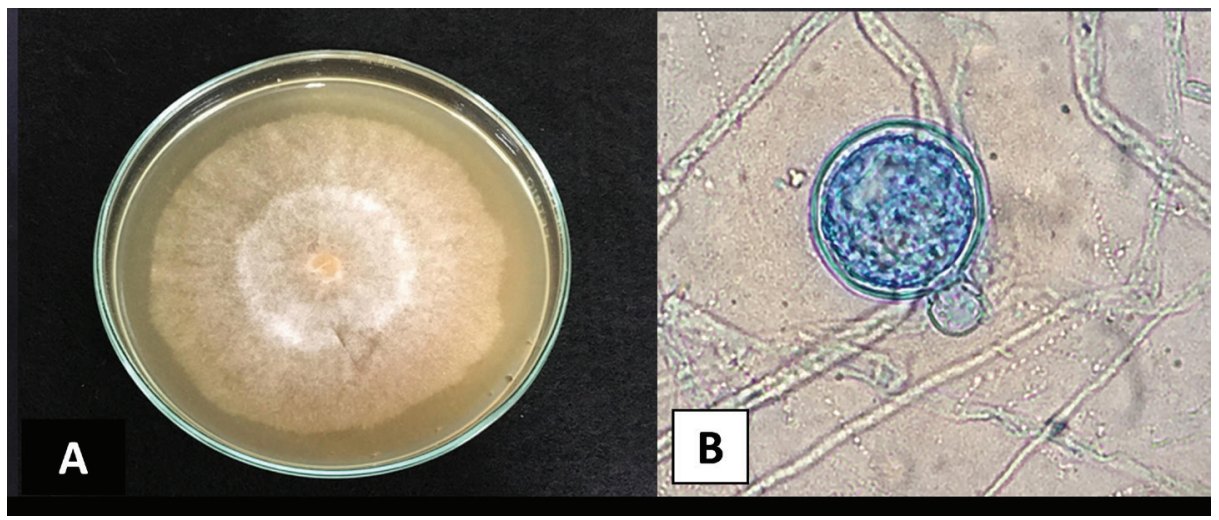

Figura 3. Características macro y microscópicas de Phytophthora sojae asociadas a muerte de plántulas de soya en la altillanura plana del departamento del Meta. A. Características macroscópicas de una colonia en medio V8 modificado. B. Oospora de P. sojae. Fuente: AGROSAVIA (2017).

aislamientos de este estudio procedentes de cultivos de soya de la región de los llanos orientales de Colombia; 5057301, 5057302, 5057303, 5057305, 5057306, 5057307 y 5057308 (Tabla 1); doce (12) cepas de referencia reportadas previamente para la especie $P$. sojae; diecinueve (21) especies tipo de Phytophthora pertenecientes a los ocho clados reportados para el género (Tabla 1); y como outgroup se empleó la cepa Pythium deliense KM597162.1. Los aislamientos colombianos procedentes del núcleo de Puerto Gaitán en el departamento del Meta presentaron una relación filogenética con probabilidad posterior igual a 1 con todos los aislamientos de referencia $P$. sojae registrados en la base de datos del GenBank procedentes de Uruguay, Estados Unidos, Corea, Francia, Japón y China, empleados en este trabajo.

Los resultados obtenidos sugirieren una estrecha relación entre aislamientos de $P$. sojae procedentes de otros países y aislamientos de los llanos orientales de Colombia. Un análisis filogenético inicial, basado en secuencias de ADN mitocondrial y nuclear, de algunos de los aislamientos de referencia utilizados en este estudio los clasificó en el clado 7b del género Phytophthora (Laviolette y Athow, 1981). El análisis corroboró la relación filogenética de probabilidad posterior igual a 1, entre las especies $P$. sojae y $P$. sinensis pertenecientes al clado 


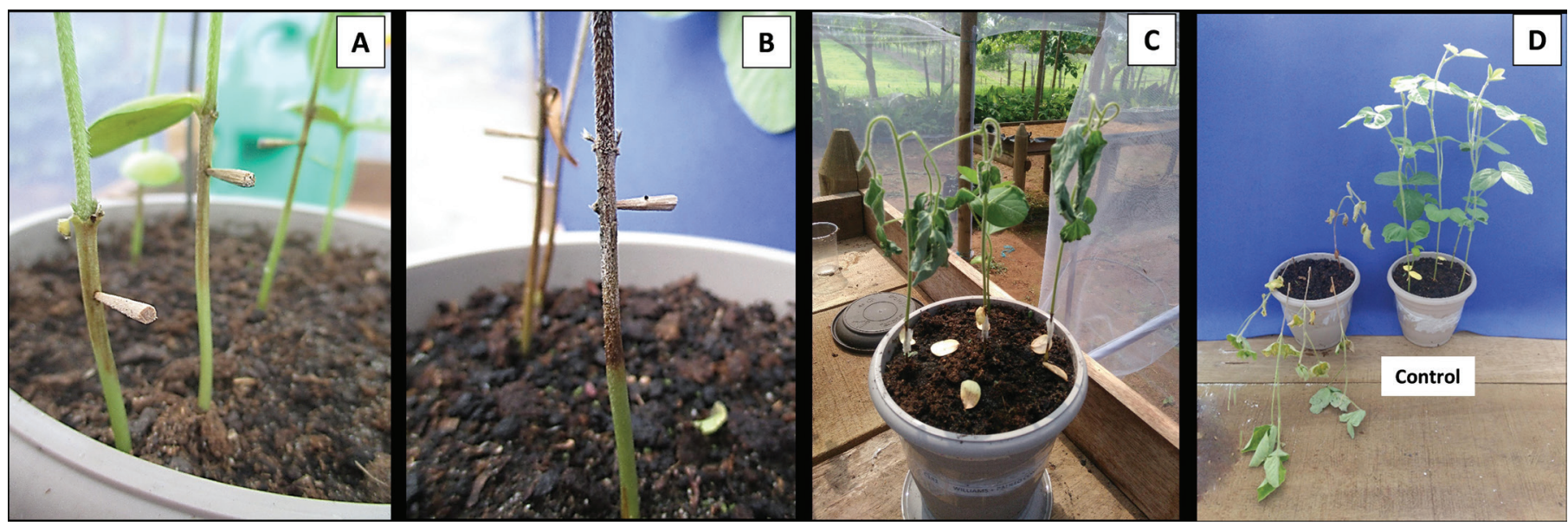

Figura 4 Pruebas de patogenicidad realizadas en la variedad de soya Williams. A. Síntomas iniciales 6 días después de la inoculación (ddi). B. Síntomas avanzados de pudrición de tallo 12 ddi. C. D. Marchitez generalizada en plantas inoculadas y control. Fuente: AGROSAVIA (2017)

$7 \mathrm{~b}$, diferenciables entre sí por la posición del anteridio con respecto al oogonio, paragino y anfigino, respectivamente de acuerdo con Kroon, (2004). De igual forma confirmó una relación filogenética existente del $100 \%$ en el clado 7 de Phytophthora, entre las especies $P$. fragarie del 7a y $P$. cinnamomi 7c, con relación a las especies $P$. sojae y $P$. sinensis del clado $7 b$ (Kroon, 2004). No se observaron relaciones filogenéticas estrechas adicionales entre el clado $7 \mathrm{y}$ otras especies tipo pertenecientes a los demás clados reportados para el género Phytophthora (Kroon, 2004). Estos hallazgos iniciales coinciden con Martin et al. (2014) y corresponden con análisis filogenéticos posteriores realizados con 7 secuencias nucleares y 4 mitocondriales donde también se ha clasificado a Phytophthora sojae en el clado 7.

En un estudio previo de Tapiero et al. (2006) orientado a determinar la diversidad entre aislamientos de $P$. sojae mediante el uso de cinco marcadores moleculares tipo microsatélites diseñados sobre secuencias ESTs (1S, 2S, 3S, 4S y 5S) (Dorrance, (2008) y Stewart et al. (2011), los microsatélites $4 \mathrm{~S}$ y $5 \mathrm{~S}$ que finalizaron el proceso de análisis exitosamente resultaron monomórficos en una colección de $P$. sojae procedente de los llanos orientales de Colombia, demostrando la baja variabilidad de los marcadores SSRs derivados de regiones codificantes intraespecie del patógeno. Estos resultados podrían coincidir con las relaciones filogenéticas de aislamientos de $P$. sojae colombianos que presentaron probabilidad posterior igual a 1 para el clado $7 \mathrm{~b}$ de Phytophthora spp. en el presente estudio. No obstante, trabajos posteriores promovieron el desarrollo de nuevos marcadores moleculares SSRs con mayor polimorfismo a partir de secuencias genómicas (Schena et al. 2008; Tyler et al. 2006). Específicamente sobre secuencias de $P$. sojae raza 2 se desarrollaron 21 marcadores SSRs. Estos marcadores fueron analizados mediante los sistemas de capilaridad ABI y CEQ, encontrándose un mayor número de alelos permitiendo a su vez, una mayor detección de diversidad genética dentro de la especie P. sojae (Stewart et al. 2011).

De acuerdo con Schoch et al. (2012), aunque las secuencias ITS son empleadas como código de barras para hongos, no resuelven del todo las relaciones filogenéticas entre poblaciones al interior de diferentes géneros, en este caso Phytophthora. Se ha reportado que su uso para análisis filogenéticos es limitado para especies relacionadas a un clado o subclado. La variación en la longitud de la región ITS analizada no permite generar un alineamiento preciso a través de todo un género, lo cual lidera una limitada resolución y bajo soporte de

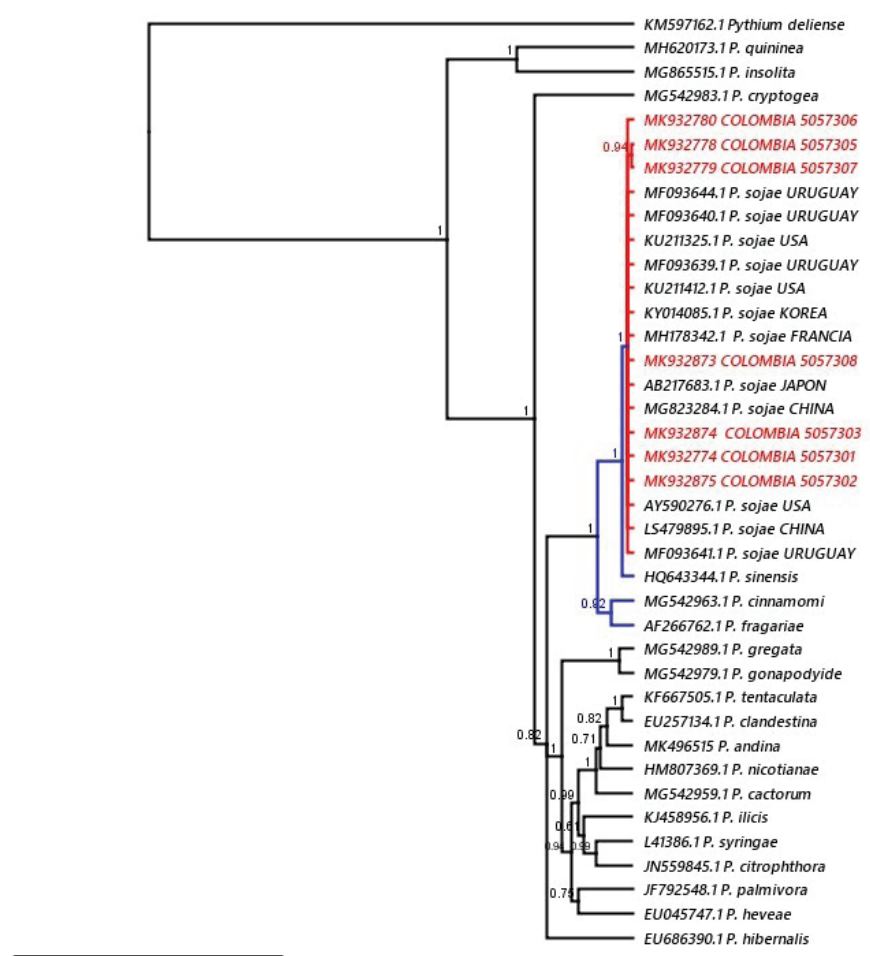

0.3

Figura 5. Árbol filogenético consenso basado en inferencia bayesiana, ilustrando la relación entre aislamientos de Phytophthora sojae. El árbol fue construido usando secuencias de la región completa del ITS-ADNr (691 pb). La cepa Pythium deliense KM597162.1 fue usada como outgroup. Los números presentes en cada clado representan las probabilidades posteriores.

repeticiones para definir relaciones filogenéticas (Laviolette y Athow, 1981). De acuerdo con Damm et al. (2012) para análisis filogenéticos más robustos se recomienda el uso de secuencias parciales informativas que codifiquen proteínas ya que sus intrones a menudo tienen más variaciones que la región ITS, como las del Factor de Elongación 1 alpha (EF-1 $\alpha$ ), actina (ACT), calmodulina (CAL), quitina sintasa (CHS-1), DNA liasa (APN2), glutamina sintetasa (GS) y manganeso superóxido dismutasa (SOD2). De igual modo, es probable que las 
Tabla 1. Descripción de unidades taxonómicas operacionales de Phytophthora spp., empleadas para el análisis filogenético.

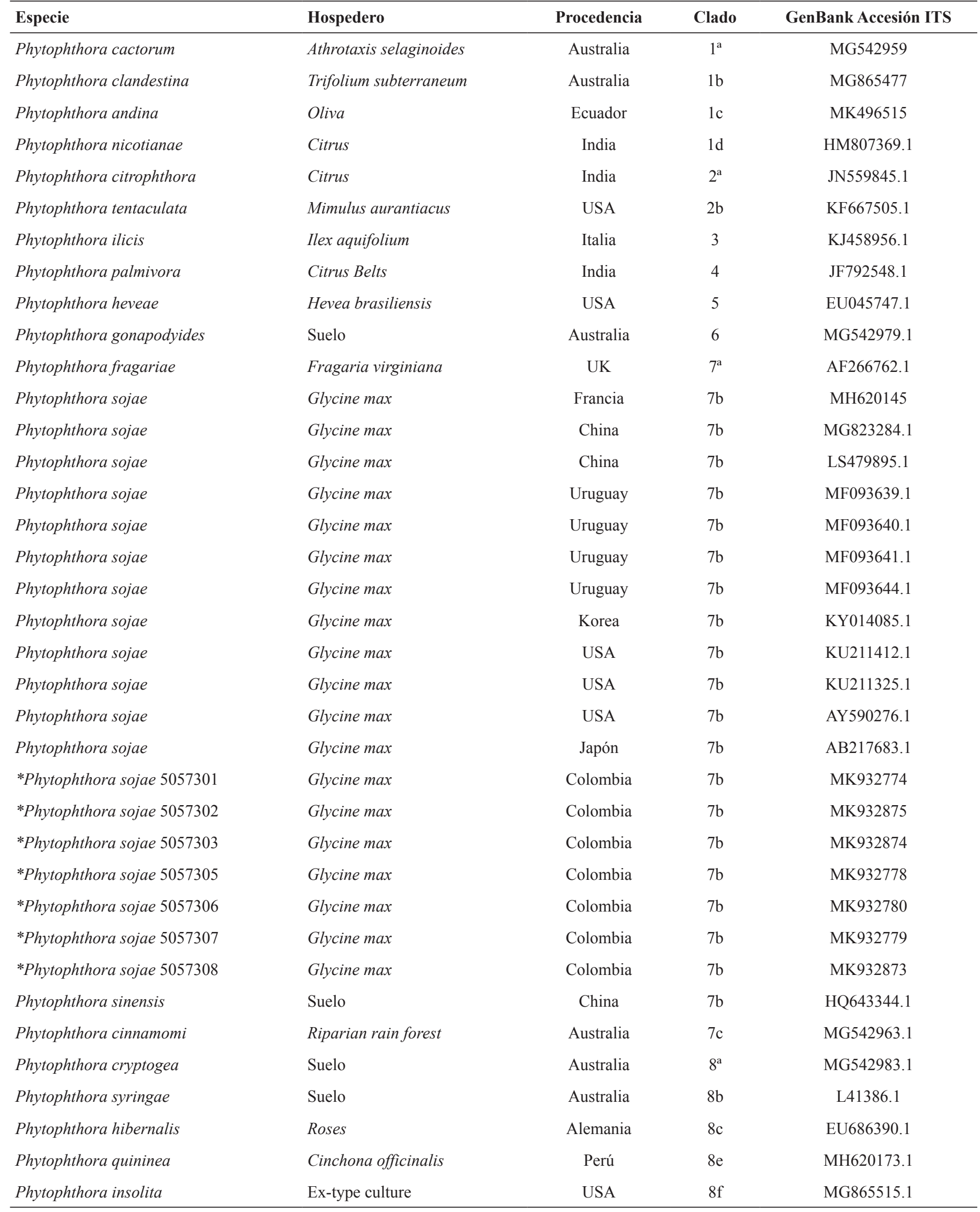


innovaciones futuras se centren cada vez más en la comprensión de las poblaciones y las relaciones entre el hospedero y el patógeno, y en el uso de análisis cada vez más sofisticados de genomas completos y marcadores moleculares que permitan conocer en detalle poblaciones de patógenos, por medio de la identificación de regiones polimórficas entre ellas (Damm et al. 2012).

Los resultados de este estudio permiten asociar el oomycete Phytophthora sojae como-agente causal de la pudrición de raíces y tallo de la soya en algunos cultivos de la altillanura plana del departamento del Meta. No obstante, su rol en el complejo "Damping off" no fue esclarecido. De las 84 muestras analizadas en el período 2015-2017, 7 muestras correspondientes al 8\% presentaron síntomas típicos de pudrición de raíz y tallo causados por $P$. sojae. Las 77 muestras restantes correspondientes al $92 \%$ presentaron síntomas del complejo "Damping off" y fueron asociados a Pythium spp. y Fusarium spp. Contrario a lo descrito por Vallone et al. (1999), Wrather et al. (2001) y Dorrance (2018), quienes reportan a Phytophthora sojae como causante de "Damping off" en pre y post emergencia de semillas. En relación a la sintomatología en baja prevalencia encontrada en este estudio y asociada a Phytophthora sojae en la altillanura colombiana, se ha reportado que este patógeno también puede causar pudrición de raíces y tallos e infecciones en plantas adultas.

Las pérdidas de rendimiento pueden alcanzar el 100\% si los cultivares susceptibles se siembran en campos que tienen historial de la enfermedad y con deficiencias en drenaje. El patógeno requiere agua libre y condiciones de suelo saturadas para el desarrollo de zoosporas y el movimiento hacia la planta huésped (Dorrance, 2018). De acuerdo con Tapiero y Rey (2006) a diferencia de lo encontrado en este estudio para la altillanura, $P$. sojae es un patógeno prevalente en el piedemonte llanero especialmente en suelos con problemas de compactación y drenaje en los que puede causar pérdidas de hasta el $23 \%$ de la producción de soya cuando presenta una incidencia del $65 \%$. Los suelos de la altillanura plana del Meta contrastan con los del piedemonte llanero, ya que presentan una mineralogía dominada por arcillas de escasa actividad, baja capacidad de intercambio catiónico, alta acidez, baja fertilidad y alto contenido de aluminio intercambiable según reportes de Botero, (1989). Así mismo, Sánchez y Cochrane (1978) mencionan que a diferencia de los suelos de piedemonte, presentan excelentes condiciones físicas que permiten evacuar los excesos de precipitación. Los suelos de la altillanura plana del Meta pertenecen al grupo de los Oxisoles (Mejía, 1996) que solo retienen cantidades muy pequeñas de agua dentro de los límites convencionales del coeficiente de marchitez permanente y capacidad de campo, y en general se ha aceptado que no pueden almacenar más de $10 \mathrm{~mm}$ por $10 \mathrm{~cm}$ de suelo (Wambeke, 1974). Esta baja retención de humedad se atribuye a la fuerte microagregación de estos suelos, que hace que se comporten como arenas en cuanto al movimiento de agua a tensiones bajas (Mejía, 1996). Las diferencias marcadas en el tipo de suelo de las dos ecorregiones nos brindan un argumento que podría explicar la baja presencia de $P$. sojae en la altillanura plana del Meta, en cuyos suelos hay menor susceptibilidad al encharcamiento y por ende hay menor predisposición para que se presente la enfermedad.

El análisis filogenético basado en la región ITS del patógeno sugirió una estrecha relación de la mayoría de los aislamientos de $P$. sojae procedentes de la altillanura plana colombiana en el departamento del Meta y los aislamientos procedentes de otros países. Con el fin de profundizar en estudios de diversidad de los aislamientos del patógeno en estudio se recomienda el uso de secuencias parciales informativas adicionales a la ITS con el fin de generar nuevos marcadores moleculares y análisis de genomas completos que permitan la determinación de regiones polimórficas entre ellos.

\section{AGRADECIMIENTOS}

Los autores agradecen al Ministerio de Agricultura y Desarrollo Rural de Colombia (MADR) por la financiación de este trabajo de investigación enmarcado en el macroproyecto "Desarrollo de estrategias tecnológicas y vinculación del conocimiento en los sistemas de producción de cultivos transitorios, en la Altillanura plana y Piedemonte Llanero" desarrollado por la Corporación Colombiana de Investigación Agropecuaria- AGROSAVIA. AAndrea Mayorga y Luis Lizarazo de AGROSAVIA C.I La Libertad por el apoyo en laboratorio y mantenimiento de las plantas en casa de malla. A los agricultores que autorizaron los muestreos en sus campos productivos.

\section{REFERENCIAS}

1. Botero, R. Manejo de explotaciones ganaderas en las sabanas bien drenadas de los Llanos Orientales de Colombia. Cali: Centro Internacional de Agricultura Tropical, 1989. 100p. (Serie Boletín Técnico 2). Disponible en: <https://cgspace.cgiar.org/bitstream/handle/10568/54487/Manejo_explotaciones_ganaderas_sabana.pdf? sequence $=1 \&$ isAllowed $=\mathrm{y}>$. Acceso en: 3 ago. 2019.

2. Corporación Colombiana de Investigación Agropecuaria. Metodología de Identificación y aislamiento de Phythopthora sojae. Villavicencio: AGROSAVIA, 2016. 24p. Informe final de meta de investigación.

3. Corporación Colombiana de Investigación Agropecuaria. Líneas élite seleccionadas por resistencia a Phytophthora sojae. Villavicencio: AGROSAVIA, 2017. 30p. Informe final de meta de investigación.

4. Corporación Colombiana de Investigación Agropecuaria. Enfermedades limitantes caracterizadas en la producción de la Soya en las principales zonas productoras del departamento del Meta y prácticas de manejo integrado seleccionadas. Villavicencio: AGROSAVIA, 2018. Informe final de proyecto de investigación.125 Pág.

5. Damm, U.; Cannon, P.F.; Woudenberg, J.H.C.; Crous, P.W. The Colletotrichum acutatum species complex. Studies in Mycology, Utrech, v.73, n.1, p.37-113, 2012.

6. Dorrance, A. Management of Phytophthora sojae of soybean: a review and future perspectives. Canadian Journal of Plant Pathology, Burnaby, v.40, n.2, p.210-219, 2018.

7. Dorrance, A.; Berry, S.A.; Anderson, T.R.; Meharg, C. Isolation, storage, pathotype characterization, and evaluation of resistance for Phytophthora sojae in soybean. Plant Health Progress, St. Paul, v.9, n.1, p. 1-10, 2008.

8. Drenth, A.; Sendall, B. Practical guide to detection and identification of Phytophthora. Brisbane: CRC for Tropical Plant Protection, 2001. 42p.

9. Erwin, D.C.; Ribeiro, O.K. Phytophthora Diseases Worldwide. St. Paul: American Phytopathological Society, 1996. 562p.

10. Granada, G.A.; Varón de Agudelo, F. Pudrición por Phytophthora en soya. Revista ASIAVA, Cali, n.19, p.17-18, 1996.

11. Guevara, Y.A. Identificación de especies de Colletotrichum spp. asociadas a la Antracnosis de tres núcleos productivos de Caucho Natural en Colombia. 2017. Tesis (Maestría em Ciencias Biológicas) - Facultad de Ciencias, Universidad Nacional de Colombia, Bogotá.

12. Keeling, B.L. A Seedling Test for Resistance to Soybean Stem Canker Caused by Diaporthe phaseolorum var. Caulivora. Phytopathology, St. Paul, v.72, n.7, p.807-809, 1982.

13. Kroon, L.P.N.M.; Bakker, F.T; Van Den Bosch, G.; Bonants P.J.M.; Flier, W.G. Phylogenetic analysis of Phytophthora species based on mitochondrial and nuclear DNA sequences. Fungal Genetics and Biology, Madison, v.41, p.766-782, 2004.

14. Laviolette, F.A.; Athow, K.L. Physiologic races of Phytophthora megasperma f. sp. glycinea in Indiana, 1973-1979. Plant Disease, St. Paul, v.65, n.11, p.884-885, 1981.

15. Martin, F.N.; Blair, J.E.; Coffey, M.D. A combined mitochondrial and nuclear multilocus phylogeny of the genus Phytophthora. Fungal Genetics and Biology, Madison, v.66, p.19-32, 2014.

16. Mejía, L. Genesis y características de los oxisoles y suelos oxicos de los llanos orientales de Colombia y su relación con la fertilidad. Suelos Ecua- 
toriales, Bogotá, v.26, n.1, p.7-34, 1996.

17. Montoya, C. Pudrición del tallo y raíz de la soya por Phytophthora en los Llanos Orientales. ASCOLFI informa, Cali, 23., 1., p.35-38, 1991.

18. Moreira, S. R.; Arrabal, C.A. Seleção de linhagens de soja da Embrapa para resistência a doenças: histórico de 2008 a 2014. 1.ed. Londrina: Embrapa Soja, 2016. 42p. (Documentos, 376).

19. Ristaino, J.B.; Madritch, M.; Trout, C.L.; Parra, G. PCR Amplification of Ribosomal DNA for Species Identification in the Plant Pathogen Genus Phytophthora. Applied and Environmental Microbiology, St. Paul, v.64, n.3, p. 948-954, 1998.

20. Sánchez, L.F.; Cochrane, T.T. Paisajes, suelos y clima de los Llanos Orientales de Colombia. In: Vera, R. R. (1985). Sistemas de producción pecuaria extensiva, Brasil, Colombia, Venezuela: Informe final proyecto ETES - 1978-1982.Calí: Centro Internacional de Agricultura Tropical CIAT,1985. p.213-224.

21. Schena, L.; Cardle, L.; Cooke, D. Use of genome sequence data in the design and testing of SSR markers for Phytophthora species. BMC Genomics, Milán, v.9, p.620, 2008

22. Schoch, C.L.; Seifert, K.A.; Huhndorf, S.; Robert, V.; Spouge, J.L.; Levesque, C.; Fungal Barcoding Consortium. Nuclear ribosomal internal transcribed spacer (ITS) region as a universal DNA barcode marker for fungi. Proceedings of the National Academy of Sciences of the USA, Washington, v.109, n.16, p.6241-6246, 2012.

23. Stewart, S.; Wickramasinghe, D.; Dorrance, A.E.; Robertson, A.E. Comparison of three microsatellite analysis methods for detecting genetic diversity in Phytophthora sojae (Stramenopila: Oomycete). Biotechnology Letters, Birmingham, v.33, n.11, p.2217, 2011.
24. Tamura, K.; Stecher, G.; Peterson, D.; Filipski, A.; Kumar, S. MEGA 6: Molecular Evolutionary Genetics Analysis version 6.0. Molecular Biology and Evolution, Oxford, v.30, n.12, p.2725-2729, 2013.

25. Tapiero, A.; Garnica, D.; Gordillo, A.; Bernal, A.; Restrepo, S. Molecular and pathogenic variability in colombian isolates of Phytophthora sojae. Phytopathology, St. Paul, v.96, n.6, p.S113, 2006.

26. Tapiero, A.; Rey, V. Capítulo 6: Manejo de las enfermedades del cultivo de la soya (Glycine max L.) en los Llanos Orientales de Colombia. In: Jaramillo, C.A.; Cubillos, N. Soya (Glycine max L.) alternativa para los sistemas de producción de la Orinoquia colombiana: Plan estratégico de Investigación y desarrollo tecnológico de la soya. 1.ed. Villavicencio: CORPOICA C.I. La Libertad, 2006. 225 p. (Manual Técnico, 9).

27. Tyler, B. M.; Tripathy, S.; Zhang, X.; Dehal, P.;Jiang, R. H.; Aerts, A.; Chapman, J. Phytophthora genome sequences uncover evolutionary origins and mechanisms of pathogenesis. Science, Washington, v.313, n.5791, p.1261-1266, 2006.

28. Vallone, S.; Botta, G.; Ploper, D.; Grijalba, P.; Gally, M.; Barreto, D.; Perez, B. Incidencia de Phytophthora sojae en cultivos de soja en las regiones Pampeana Norte y Noroccidental de Argentina. Actas Mercosoja 99, Rosario, p. 21-25, 1999.

29. Wambeke, A. Management properties of ferralsols. Rome: FAO, 1974. (Soils Bulletin, 23).

30. Wrather, J.A.; Stienstra, W.C.; Koenning, S.R. Soybean disease loss estimates for the United States from 1996 to 1998. Canadian Journal of Plant Pathology, Burnaby, v.23, n.2, p.122-131, 2001. 